\title{
DEVELOPMENTS IN THE DESIGN OF DUCTILE REINFORCED CONCRETE FRAMES
}

\author{
T. Paulay*
}

\begin{abstract}
SYNOPSIS
A condensed step by step summary of the application of a recently published capacity design philosophy, as applied to earthquake resisting ductile reinforced concrete frames, is presented. The theoretical inelastic dynamic response of three prototype frames, so designed and subjected to particularly severe seismic excitations, is then reported. It is shown how the predicted maximum actions compare with those used in the design. The design quantities, derived from a modified conventional elastic frame analysis for a code specified lateral static loading, were found to ensure a very high degree of, and yet economical and practical, protection against hinging in columns at and above the first floor.
\end{abstract}

\section{INTRODUCTION}

It is generally recognized in seismic design that few structures will be able to respond elastically to intense seismic ground excitations. Therefore damage, associated with excursions beyond the elastic limit, that may occur during less frequent earthquakes to be expected in the locality, is accepted. The overriding criterion of the design process is an assurance that the structure will possess properties that will enable it to survive the largest expected earthquake, without collapse. While existing code requirements $(1,2,3)$, that specify equivalent lateral design' loads of certain intensities, ensure a high degree of protection against all forms of damage during frequent small disturbances, procedures that could lead to a comparable assurance that collapse will not occur during the largest credible excitation, are not sufficiently formalized. The formulation of the "capacity design philosophy" in New Zealand, (4) to be reviewed subsequently, represents a significant advance in this respect. However, the process of quantifying minimum required strengths in simple terms has not yet been completed.

The concepts of a desirable hierarchy in the development of energy dissipation mechanisms, to be mobilized during catastrophic earthquakes, has gradually been clarified. For multistorey rigid jointed reinforced concrete frames, this hierarchy requires that plastic hinges develop in beams first and that "soft storey" column failure mechanisms be avoided. This paper describes the response of some frames that have been designed in accordance with these principles.

The evaluation of design actions, and the consideration of the concurrency of actions that could result at any particular section during the inelastic dynamic response of a frame, involve complex and time consuming computational efforts. Probabilistic modal superposition techniques have been used to evaluate likely maxima that may occur during the elastic response

* Professor of Civil Engineering, University of Canterbury, Christchurch. of the structure. The predominantly inelastic nature of the structural response is, however, not sufficiently recognised by these techniques. Moreover, the designer is still required to use his judgement if a quantification of the hierarchy in the development of failure mechanism is to be established.

Time history analyses of the inelastic dynamic response of frames to given ground excitations are likely to furnish the most reliable information with respect to behaviour. Unfortunately these are analyses rather than design techniques. They are very useful in verifying the viability of the design but the results must be combined with the likely relevance of the chosen earthquake motion to local seismicity. At the present few designers in New Zealand will be in the position to carry out a series of such analyses, to verify the response of the frame they designed to a range of selected ground motions.

The application of a simple, deterministric design philosophy, relevant to ductile multistorey frames, which utilizes the equivalent lateral static forces prescribed by many building codes, has been suggested $(5,6)$. The main feature of this approach is that structural actions, such as bending moments, shear and axial forces, derived from a static analysis, are subsequently modified for various members. This is done in recognition of the likely effects encountered during the inelastic dynamic earthquake response, and to ensure the desired hierarchy in the development of yield mechanisms. The values of magnification factors were based upon a limited number of case studies. Further refinements in the selection of these values are to be expected with the continuation of this study.

The procedure is deterministic to the extent that it imparts member strength properties that are likely to ensure that no inelastic deformations of any significance will occur in localities of the structure, not specifically assigned to dissipate energy, during severe earthquake excitations with a wide range of spectral characteristics. 
An important aim in the development of the design technique was simplicity. Lack of precision was compensated for by deliberate conservatism in the selection of certain numerical values. In spite of this, these case studies indicate that, when compared with current design practice, some reduction in structural materials results. Moreover, congestion of reinforcement in columns examined appears to have been reduced considerably.

In the following section details of the frame design procedure $(5,7)$ are restated step by step. Subsequently the response to some severe ground motions of three prototype frames, so designed, is presented. In the light of the findings suggestions are made on how further improvements in the design procedure could be achieved.

\section{THE MAJOR STEPS IN THE CAPACITY DESIGN OF DUCTILE FRAMES}

In the capacity design of earthquakeresisting structures, primary energydissipating elements of mechanisms are chosen and suitably detailed, while other structural elements are provided with sufficient reserve strength capacity, to ensure that the chosen primary energy dissipating mechanisms are maintained at near full strength throughout the deformations that may occur $(1,4)$

The major steps of a previously published technique of capacity design philosophy, applied to reinforced concrete ductile frames, $(5,7)$ is briefly summarized in the following:

Step 1 - Using an appropriate elastic analysis, the bending moments for beams and columns of the frame are derived for the specified lateral static(1) earthquake load only. Approximate analyses(8) are acceptable for this purpose. $M_{\text {code }}$ refers to moments so derived.

Step 2 - The beam bending moments so obtained are superimposed upon moments induced by the appropriately factored gravity loads.

Step 3 - To minimize demands for excessive flexural reinforcement, particularly in negative moment zones, and to utilize flexural strengths stipulated by minimum code requirements, typically involving the bottom flexural reinforcement at beam supports $(7,9)$ a redistribution of design moments, $(6,7,10)$ is now carried out. Skilful moment redistribution along continuous beams of ductile frames will not only lead to more advantageous arrangement of flexural reinforcement, but it will also considerably reduce design quantities for the columns, resulting in appreciable saving in column reinforcement. Moment redistribution is justifiable because the stipulated lateral static load(1) or appropriately factored static load $(2,3,9)$ is intended to be sustained by an inelastic rather than an elastic frame.

Step 4 - All critical beam sections are designed and details of the reinforcement for all beams of the frame are finalized. The subsequent design of other elements will depend on the likely maximum strength that could be developed in the beams as detailed at this stage.
Step 5 - The flexural overcapacity $(4,7)$ of each potential plastic hinge, as detailed, is now evaluated in each span of each continuous beam for both directions of the applied lateral load. From an extrapolation of bending moment diagrams extending over the clear spans, or otherwise, the corresponding beam overstrength moments at each column centre line are found and hence the associated moment induced beam shear forces, $V_{o e}$, in each span are determined.

Step 6 - The beam overstrength factor, $\phi_{0}$ ' at the centre line of each column, for both directions of the loading on the frame are determined. For special localities specific values of $\phi_{0}$ have been suggested $(5,7)$.

The beam overstrength factor at a column, $\phi_{0}$, is the ratio of the sum of the flexural overstrengths developed by the beams, as detailed, to the sum of the flexural strengths required in the given direction by the code specified lateral seismic loading(1) alone, both sets of values being related to the centre line of the relevant column $(7)$. In other words, the factor relates maximum feasible beam strengths, that can be extracted at a beam-column joint, to corresponding strengths stipulated by the loading code ${ }^{(1)}$.

Step 7 - At each floor the appropriate value of the dynamic moment magnification factor, $\omega(5,7)$ is established. This moment magnification intends to allow for the fact that during the dynamic excitation the moment pattern along a column may be markedly different from that which resulted from the initial elastic analysis. To illustrate the phenomenon Fig. 1 is presented. It compares bending moment patterns for one column, computed at various critical instants of the inelastic seismic response of a twelve storey frame, with the moments derived by an elastic analysis for the specified lateral static loads.

The following equation has been suggested for the evaluation of the dynamic moment magnification factor for one way frames:

$1.2<\omega=0.6 \mathrm{~T}_{1}+0.85<1.8$

where $\mathrm{T}_{1}$ is the fundamental period of the building in seconds. At and near the ground floor and in the top storey, specific values for $\omega$ have been suggested $(5,7)$. The maximum expected column moment, measured at immediately below or above the level of beam centre lines may then be obtained from the product $\phi_{0} \omega \mathrm{M}_{\text {code }}$.

Step 8 - In order to arrive at probable maxima for earthquake induced column axial loads, all maximum earthquake induced beam shear forces, $V_{\text {oe }}$, for all floors from roof level down to the first floor, are computed and hence at each floor the axial force $P_{e q}=R_{V} \sum V_{o e}$ is determined. The reduction factor $\mathrm{R}_{\mathrm{V}}$ recognizes the diminishing likelihood of the beam overstrength shear forces, $V_{\text {oe }}$, developing simultaneously with increasing number of floors, above the level that is being considered (5). $R_{v}$ also intends to compensate for the reduced likelihood of locally magnified moments, thought to be due to higher mode effects, coinciding 
with maximum earthquake induced axial forces that are primarily due to a first mode response.

This approach is similar to that adopted in other countries to reduce overturning moment effects with increasing number of floors taken from roof level $(2,3,11)$.

Step 9 - After the combination of the earthquake induced axial load, $\mathrm{P}_{\text {eg, }}$, with appropriately factored gravity loads, the design axial load on the column, $\mathrm{P}_{e}$, for each direction of seismic action can now be found.

Step 10 - The column design shear force in each storey is estimated from

$\mathrm{V}_{\mathrm{Col}}=1.4 \phi_{\mathrm{O}}, \max . \mathrm{V}_{\text {code }}$

where $\phi_{0}, \max$. is the larger of the two beam overstrength factors relevant to the ends of a column, and $V_{\text {code }}$ is the column shear force derived from the initial elastic analysis for the specified lateral earthquake loading (1) only. As the optimum average value of $\phi_{0}$ is 1.4 , it will be seen that the column design shear force will seldom be less than twice the shear force derived from the initial elastic analysis for code loading. The special consideration of first storey columns is discussed in Section 4.5 .

The critical column design moments at the top or the soffit of beams, to be considered together with the design axial load $\mathrm{P}_{e}$, are finally found from

$M_{\text {Col }}=\phi_{0} \omega M_{\text {code }}-0.3 h_{b} v_{\text {col }}$

where $h_{b}$ is the depth of the beam which frames into the column at the floor under consideration.

Step 11 - In columns under low axial compression or subject to axial tension relatively "early" yielding is considered to be acceptable. Consequently a reduced column design moment, given by

$\mathrm{M}_{\mathrm{Col}}$, reduced $=\mathrm{R}_{\mathrm{m}} \mathrm{M}$ Col

may be considered. The reduction factor $R_{m}$ takes the axial load intensity and the dynamic moment magnification factor, $w$, into account $(5,7)$.

Step 12 - With the determination of the design moments, axial and shear forces, the section properties at each level of the columns may be determined so as to give ideal strengths not less than those required. Capacity reduction factors, normally used in reinforced concrete design $(7,9)$, are all taken as unity in this capacity design procedure.

\section{A STUDY OF PROTOTYPE FRAMES}

To examine in greater detail the suitability of the capacity design procedure based on previous limited studies $(12,13)$ and outlined in the previous section, three prototype two-bay frames with 6,12 and 18 storeys were chosen for detailed study(14).

Each structure was loaded in accordance with the provisions of the New Zealand loading and general design code ${ }^{(1)}$ and then designed as outlined in the preceding section. Simple interior two-bay frames of a building, resisting earthquake loads in one direction only, were chosen. Other elements, such as shear walls, were assumed to resist seismic actions perpendicular to the plane of these frames. To avoid excessive reserve strength that could possibly mask some aspect of behaviour, care was taken in the proportioning of members to represent, as closely as possible, the minimum requirements of the proposed design procedure.

The unreduced live load for all frames was $2.5 \mathrm{kPa}$. Actions for the prescribed lateral static load $(1)$ were deriveg using Muto's approximate frame analysis $(8)$. The lateral deflections at each floor were estimated from the average of the deformations computed for two columns, which showed good correlation at all levels. Significant data for these frames are assembled in Table I.

The time history studies for various ground excitations were carried out mainly using a 2-dimensional dynamic analysis developed by Sharpe $(15)$. Certain obvious errors, attributed to overshoots in the process of successive approximations, resulted in a decision to repeat some of these analyses using a different program, developed by Powell(16). In terms of structural design the differences in the results, obtained from these two programmes, were not significant. Both analyses led to the same overall assessment of structural performance.

To compensate for the effects of cracking, $25 \%$ and $50 \%$ loss of stiffness with respect to uncracked member sections was allowed in columns and beams respectively. $8 \%$ of critical damping was assumed in the first and the $n$th mode of vibration, where $\mathrm{n}$ is the number of storeys. The programme then allocated values less than $8 \%$ critical damping for modes between 1 and $n$, and larger values beyond mode $n$. $10 \%$ critical damping was used for the first two modes in the DRAIN-2D $(16)$ programme.

The permanent gravity load during dynamic excitation was simulated by the dead and one third of the design live load.

Member moment capacities were expressed in terms of probable material properties, but some reduction was allowed to compensate for overestimates that are frequently made in the program before yielding is detected. The guaranteed yield strength of the main reinforcement in the beams and columns was taken as $275 \mathrm{MPa}$ and $415 \mathrm{MPa}$ respectively. Moment curvature relationships were represented by elastic-perfectly plastic hysteresis loops without allowance for stiffness degradation or strain hardening.

Wherever applicable comparison of computed actions during the response are made in the diagrams with those stipulated by the loading code $(1)$. To make the comparison more meaningful the code specified actions (1) were inflated by $23 \%$. This was considered to correspond with the probable strength of the structure that would have been designed so as to satisfy exactly code 
specified lateral static load requirements, without the use of any magnifying factors of the proposed design procedure.

Because of time limits and expense, only a few selected ground acceleration records could be used in this study. The $2 \%$ damped pseudo velocity response spectra of the are shown in Fig. 2. The records to be used in the analyses, as shown in Table I and Fig. 2 , were selected so as to give the maximum likely response in the region of the fundamental period for each of the frames studied. Because of its extensive use in similar studies, the El Centro $1940 \mathrm{~N}-\mathrm{S}$ record was used as a bench mark for all structures.

In the assessment of the column responses, the appropriate moment-axial load interaction relationship for each column section was simulated by a cubic function that gave exact values at four equidistant points within the predictable range of axial load intensities i.e. $0<\mathrm{P}_{e} / f_{C}^{\prime} A_{g}<0.6$.

\section{A COMPARISON OF FRAME RESPONSES TO DIFFERENT EARTHQUAKE MOTIONS}

\section{1 - Displacements and Interstorey Drifts}

A convenient way to study the overall response of a multistorey frame to a selected earthquake ground motion, is to examine the horizontal deflection at roof level. For convenience the analytical results for all three frames studied are assembled in Fig. 3. The lateral displacement of the top floor, is shown in millimetres as well as in terms of the total building height, $\mathrm{H}$. A deflection equal to $\mathrm{H} / 100$ is shown with a dashed line because this quantity represents closely the maximum average storey drift, suggested by the New Zealand design and loading code(1) to be acceptable. For the frames studied this deflection, to be estimated in a routine design, (I) is 2.5 times the elastic deflection induced by the specified lateral static loading(1). In this allowance is made for the reduction of stiffness resulting from cracking in various members.

From Fig. 3 it is seen that this code limit on deflection has not been exceeded in any of the frames during the El Centro excitations. However, with the exception of the 19 storey frame, larger displacements were indicated by the dynamic analyses for all other of the selected ground motions.

of particular interest is the permanent inelastic displacement imposed by both the Pacoima and the Parkfield excitations after approximately 8 seconds of duration. The permanent tilt of the 12 storey frame is of the same order as the maximum distortion encountered during 14 seconds of the Pacoima excitation. After the first major inelastic excursions of the Pacoima and Parkfield motions the six storey frame oscillated about an axis on an approximate slope of 1 in 200.

For reasons of economy the analysis for the 18 storey frame was carried out for only the first 10 seconds of the excitations. As will be seen in subsequent sections the response of this frame was the least critical in all respects. No inelastic distortions were expected to occur in the frames beyond the time of 14 seconds. These permanent displacements may be taken as a measure of the severe damage that would have to be expected. From several earlier studies it became evident that these permanent drifts developed only in the later stages of the excitations and that their magnitudes were rather sensitive to the assumptions with regards viscous damping. With a reduction in the assumed fraction of critical damping the permanent drifts were found to increase.

As may be seen in Fig. 2, the Pacoima record was not expected to produce particularly critical conditions for the six storey frame. The analysis showed, however, (Fig. $3 a)$ that these motions resulted in maximum responses in all the frames studied.

In considering non-structural damage and the relative influence of $\mathrm{P}$-delta moments, the interstorey drift is of particular importance. These are presented both in absolute magnitudes and in terms of the storey height, $h$, in Fig. 5. Whereas the storey drifts are well within the intended code limit of $h / 100(1)$ for the El Centro excitations, they are much larger for the other earthquake motions. The influence of P-delta moments has not been taken into account in the modelling for the inelastic dynamic frame analysis. From preliminary studies and from the work of Powell and Row (19) it appears that the increase in inelastic displacements due to P-delta effects is not very significant.

Some indication of the significance of interstorey drifts and the associated P-delta effects on these frames may be gained from the evaluation of a stability factor $(20)$

$\mathrm{R}_{r}=\mathrm{w}_{t r} \delta / \Sigma \mathrm{M}_{i}$

where $W_{t r}$ is the total laterally displaced gravity load considered at floor $r, \delta$ is the interstorey drift and $\Sigma M_{i}$ is the sum of the ideal beam capacities developed at the beam plastic hinges at the floor considered. The factor simply expresses the fraction of the total beam strength required to sustain the P-delta moment in the storey. Thus the lateral load resistance of the beams at the particular floor is reduced by this fraction. For the most critical excitation and storey the value of $R_{r}$ was found to be $0.18,0.37$ and 0.21 for the 6,12 and 18 storey frames respectively. After 11 seconds of the Pacoima excitation about one third of the ideal beam strength in the 12 storey frame were required to resist the overturning moments caused by the large permanent inelastic storey drifts.

\section{2 - Plastic Hinge Formation}

The intention of the design was to ensure that no storey mechanisms will form during the largest excitation and that the likelihood of plastic hinge formation in any but the top and bottom storey columns is minimized. The 12 and 18 storey frames met this criteria to the extent that, with the exception of ground floor, the analysis has indicated no yielding in any column during any of the selected ground motions. The required energy during the very significant inelastic displacements was predominantly dissipated in all frames by plastic hinges in beams. 
Hinge patterns observed in the 12 storey frame during selected instants of the Pacoima Dam excitation are presented in Fig. 4, where a distinction is made between clockwise and anticlockwise relative hinge rotations that were required to mobilize the probable flexural capacity at the end of that member. For the framed instants in this figure, shown under a particular set of plastic hinges, the approximate distorted shape of the structure has also been plotted. These are seen in the insert of Fig. 4. These deflection and hinge patterns should be studied in conjunction with the roof level displacements shown for this excitation in Fig. 3b.

Contrary to expectations, at one instant ( 3.05 seconds) $96 \%$ of the possible beam plastic hinges were mobilized. It is also seen that there were only 4 brief periods during which plastic hinges at the base of the columns of this frame were predicted.

Because of the significant inelastic distortions that occurred during the first major pulse, at approximately 3 seconds, the subsequent deflection and the hinge patterns can not be related to higher mode shapes. The hinge patterns when studied in conjunction with Fig. 3, confirm that the number of load reversals, involving the formation of plastic hinges, was relatively small during the vigorous response of the frame during the first 9 seconds.

Similar hinge patterns were obtained for the 18 storey frame(14). Hinge developments at the base of the columns were, however, less frequent.

The six storey frame developed at least at one instant ( 3.71 seconds) of the Pacoima motions a complete failure mechanism with 27 plastic hinges. During both the Pacoima and the Parkfield excitations, yielding, particularly at the top end of a number of upper storey columns, occurred simultaneously with hinge formation at the base of the columns. This was the first indication that the suggested design procedure was least conservative when applied to the six storey frame. It was also noted that maximum displacement at roof level did not coincide with the development of the maximum number of plastic hinges.

\section{3 - Column Moment Demands}

In order to assess the relevance of the design intentions to the "observed" behaviour in this analytical study, the maxima of column bending moments at beam centre lines are compared in a series of figures. The dark central shaded pattern in Fig. 6 shows the bending moment diagrams for the interior column of the six storey frame, that resulted from an elastic analysis for the code specified lateral static loading. As described in Section 3, those moments have been scaled up by $23 \%$ to correspond with the ideal flexural strength that would have been obtained for the various column sections. The horizontally shaded broken line indicates the moment values that were obtained from the suggested design procedure, summarized in section 2. Only the peak values are to be considered in these diagrams as the slopes, selected only for convenience, have no relevance to any specific moment gradient.

It is seen that in the lower storeys the moments induced during the El Centro motions are of the same order as the design moments. For the Parkfield and particularly for the Pacoima excitation, the "observed" moments exceed the design moments at all levels. As a consequence, with the exception of the first floor, plastic hinge formation was indicated in the columns at all floors. As is seen these "observed" hinging moments are at times considerably larger than the design moments. The main reason for this was that, to be practical, at some sections a little more reinforcement was provided in the columns than required by the design moments. It should be noted that in the columns of the 6 storey frame only the minimum $(7,9)$ 1\% vertical reinforcing content was used.

Fig. 7 shows a similar comparison for the moments along the exterior column of the 12 storey frame. For this long period frame the maximum value of the dynamic magnification factor, $\omega$, given by Fig. resulted in design moments considerably larger than those resulting from the specified code loading(I). With the exception of the bottom and top storeys, the moments generated during the El Centro motions were much smaller than the proposed design moments. However, during the Pacoima excitation the "observed" peak moments were of the same order as those used in the design. The moments induced at the tops of the columns, up till the 7 th floor, have slightly exceeded the design moments. However, because of some excess column reinforcement and an advantageous interacting axial compression at these sections, no yielding was "observed". It may be said that for the 12 storey frame the design moments predicted very satisfactorily the column flexural demand for the critical pacoima ground motions.

The manner in which the inelastic dynamic response may affect the bending moment patterns, is shown in Fig. 1 for an exterior column of the 12 storey frame. The instantaneous moment patterns and associated hinge formation, shown there for the Pacoima excitation, may be combined with the information given also in Fig. 4. The moment pattern and the deflected shape at 2.70 seconds indicates a distinct second mode response. Similar moment patterns at 7.80 and 8.00 seconds, however, can no longer be related to a corresponding modal shape. At neither of these instants did critical column moments occur. It is seen that at 3.09 seconds a predominantly first mode moment pattern has been affected and hence distorted by a second mode response, resulting in very large column moments between the 2 nd and the 5 th floors. It is this phenomenon, which the dynamic magnification, $\omega$, is intended to compensate for.

Only the results of the Pacoima excitations are compared in Fig. 8 with the code specified flexural strengths for the exterior columns of the 18 storey frame. The maximum moments during the El Centro and the artificial A2 motions were found to be much smaller and, for the sake of clarity, corresponding plots have been omitted. It is seen that the design moments predicted very satisfactorily the peak moments for the lower 
half of the frame. In spite of structural symmetry the peak moments for the two exterior columns are not the same. This is due to the difference in beam hinging moment input at a floor (the positive and negative flexural strengths of the beams at a plastic hinge are not necessarily the same), and the great difference in earthquake induced axial forces that occur in the two columns at the same instants. Note that the hinging base moment in the compression column (column 3 at 2.81 seconds) is some $30 \%$ larger than a similar moment in the tension column (column 1 at 2.76 seconds). These "observed" base moments are much larger than the original design moments because the latter required less than $1 \%$ total reinforcement content, which has been provided. Only two load reversals, involving plastic hinge moments at the base of these columns, were "observed".

\section{4 - Demands for Inelastic Deformations}

One of the aims of this study was to estimate the ductility demand imposed on various plastic hinges during selected excitations, so that comparisons can be made with realistic values obtained from experiments. It has been found that in plastic hinges of beams of normal geometric proportions, such as used in these ductile frames, which have been suitably detailed to ensure that failure due to shear, anchorage and buckling of compression reinforcement does not interfere with the development of flexural capacity, a total rotation of 0.035 radians i.e. 2 degrees, can be attained. In laboratory studies rotations of this order were imposed on beams in both directions of loading with insignificant reduction of strength after 4 to 6 reversals of loading. Plastic hinge rotations so measured include deformations from all sources i.e. flexure, shear and anchorage slip, while the ideal beam strength is maintained.

Fig. 9 presents the envelopes for the maximum hinge rotations for all three frames, encountered at any of the four beam hinges at a floor. It is seen that the maximum hinge rotations, which occurred at the lower floors, did not approach 0.035 radians during any of the earthquakes used in the analyses. It may be said that with standard(7) seismic detailing, the predicted ductility demand could have been comfortably met by these beams. It is likely, however, that more significant strength degradation would have occurred in the first floor beams of the 6 storey frame, particularly during the Pacoima motions, because up to 18 load reversals, involving full flexural strength, were encountered in the first 10 seconds. However, only 7 instants involved ductility demands of significance. The El Centro excitation caused consistently small inelastic deformations.

The maximum plastic rotation at the base of the columns may be considered to be the most critical aspect of this study. A base hinge rotation of 0.0155 in the 12 storey frame "occurred" during the Pacoima excitation, when the total axial compression load on the column produced, an average stress of $0.55 f_{c}^{\prime}$ over the gross sectional area.*

* $f_{C}^{\prime}$ is the assumed compressive strength of the concrete.
The column section in question was therefore compression dominated, and concrete compression strains considerably in excess of 0.003 would have been required in the plastic hinge zone in order to develop the necessary plastic rotation. However, this could have been achieved with suitable confining hoop reinforcement in the end zone of the column $(1,21)$. Axial compression of similar intensity coexisted with the plastic hinge formation at the base of the 18 storey columns, where the ductility demand was, however, considerably less. The axial compression on the columns of the 6 storey frame was not critical and this would have allowed the yse of less confining hoop reinforcement $(2 I)$ to ensure adequate ductility.

The ductility demand at the base of the columns was not critical in any of the frames during the El Centro excitation. Even though intermittent column hinging occurred in the upper storeys of the six storey frame during the Pacoima Dam motions, the associated plastic deformations were insignificant, as may be seen in Fig. 9a.

\section{5 - Shear Forces Across Columns}

Dynamic analyses of inelastic structures for typical earthquake motions usually predict induced shear forces across columns which are considerably larger than those predicted by procedures prescribed by existing building codes $(1,2)$. Some codes have recognized this discrepancy and hence they stipulated that shear forces obtained from conventional seismic analyses be increased with the use of a specified load factor(2). Instead of using a uniform increase of shear for all cases, the procedure employed in the design of these frames considers the realistic beam input to the column at each floor, and also makes allowance for the possible increase of moment gradient along each column due to local effects of higher mode dynamic responses. Eq. (2) embodies these considerations. The various shear envelopes are compared in Fig. 10 for the three frames studied, details of which are discussed in relation to the six storey frame (see Fig. 10a).

The innermost stepped line represents the shear force in each storey for the interior column of the 6 storey frame, derived from the code(1) specified equivalent lateral loading. The shear forces so obtained have been increased to represent the probable shear strength of the column and these are the values shown in Fig. 10 The outermost stepped and shaded line shows the ideal shear strength obtained from Eq. (2), and it must be assumed that the column has been designed to possess at least this ideal shear strength. It is seen that at all floors the Pacoima Dam excitation produced the largest shear forces. To enable a quantitative evaluation of the critical nature of the shear forces shown, the contribution of beam shear resisting mechanisms other than stirrups (4) at a nominal shear stress of $0.17 \sqrt{f_{C}^{\prime}}$ (MPa) and with a probable compression strength of the concrete, $f_{C}^{\prime}$ ' is also shown by the shaded area. This is purely a reference strength which shows for the column under study that nominal web reinforcement is 
likely to be sufficient to provide the additional shear strength required.

The design of first storey columns for shear is different because plastic hinge formation at the base, possibly developing the flexural overstrength capacity of that section, $\mathrm{M}_{\mathrm{O}, \mathrm{col}}$ must be considered. Therefore the evaluation of the ideal shear strength, to be provided in first storey columns, was based on

$v_{C O l}=\frac{1.15}{l_{C}}\left(M_{0, c o l}+\omega \phi_{O} M_{\text {code, }}\right.$ min $)$

where $\mathrm{M}_{\text {code, }}$ min is the theoretical value of the column moment at the centre line of the first floor beams due to the code specified lateral static loading. These values are incorporated into Fig. 10.

Fig. lob makes a similar comparison of shear envelopes for the interior column of the 12 storey frame. It is seen that the proposed ideal design shear strengths, i.e. Eq. (2) and Eq. (6), consistently exceed the dynamic shear forces "observed" in the analytical studies. The conservatism demonstrated is not excessive. The minimum reinforcing content of $1 \%$ at the base of this interior column can develop a moment considerably larger than contemplated (see also Fig. 7). To be consistent in the established hierarchy of failure mechanism, allowance must be made for the possibly large shear force associated with the large base moment capacity. This explains the seemingly excessive design shear shown for the lst storey in Fig. 10b. The dynamic analysis used did not allow for strength increase in plastic hinges due to strain hardening of the column reinforcement.

Fig. 10c combines the shear forces for all three columns across each storey of the 18 storey frame. This is termed the storey shear. The critical nature of the Pacoima Dam excitation and the conservatism of the proposed procedure are again evident. The reasons for the increase in the first storey design shears are the same as outlined for the 12 storey frame. All columns of this frame develop excess flexural capacity at the base with minimum steel content. In spite of this apparent conservatism the amount of transverse steel at the base of these columns will not be governed by shear demand but rather by the confinement requirements.

\section{6 - Column Axial Forces}

The envelopes for the maximum and minimum axial compression forces for the exterior columns of the 12 and 18 storey frames are compared in Fig. 11. No net tension could be induced in columns of this study.

The design axial load envelopes were based on the load combinations $\mathrm{D}+1.3 \mathrm{~L}_{\mathrm{R}}+$ $\mathrm{R}_{\mathrm{V}} \mathrm{E}^{\mathrm{O}}$ and $0.9 \mathrm{D}-\mathrm{R}_{\mathrm{V}} \mathrm{E}^{\mathrm{O}}$, where $\mathrm{D}$ and $\mathrm{L}_{\mathrm{R}}$ represent dead and reduced live loads respectively, $\mathrm{E}^{\mathrm{O}}$ considers earthquake induced axial loads, originating from the plastic hinge moments at overstrength in all beams, and $R_{\mathrm{v}}$ is an axial load reduction factor discussed in Step 8 of section 2 .

It is seen that a good agreement exists between the proposed design values and the "observed" axial forces. The maximum compressive forces during the Pacoima Dam motions slightly but consistently exceed the design intensities. On the other hand the minimum design axial compression which, when combined with the design column moments, is likely to govern in the requirements for the principal column reinforcement, is generally less and therefore it is more critical than the "observed" values.

As axial forces are considered together with likely concurrent bending moments, a high degree of accuracy in their determination is not warranted. An error of the order seen in Fig. 12, will only slightly affect the flexural capacity of the column sections, which has been adequately provided for, as may be seen in Figs. 7 and 8 .

The reduction factor $R_{V}$ has a negligible effect on the column forces of the 6 storey frame. Therefore the conservatively predicted and less critical axial forces for this frame are not reproduced here.

\section{SUMMARY AND CONCLUSIONS}

\section{1 - The Aims of the Design Procedure}

The principal aim of the proposed design procedure is to quantify a capacity design philosophy, as applied to multistorey ductile frames. Thereby, with the exception at ground floor level, columns are provided with a high degree of protection against possible hinging during a very large earthquake. The study of three prototype frames indicates that this aim was largely satisfied.

By using magnification factors that recognize the probable strengths of the primary energy dissipating mechanisms, i.e. the beams, as built, and the dynamic characteristics of a frame, a more consistent protection of columns may be achieved than with the use of existing global factors.

\section{2 - Overall Frame Behaviour}

The predicted behaviour of the 12 and 18 storey frames was seen to be very satisfactory with respect to all of the selected earthquake motions. The largest damage was indicated for the 6 storey frame, particularly during the Pacoima Dam motions. It is thought that the reason for this is primarily the relative conservatism with respect to long period structures inherent in the specified tri-linear spectrum of the New Zealand loading and design code(1). The two taller frames were rather flexible and thus they were placed well beyond the longest fundamental period of 1.2 seconds, beyond which no reduction of the base shear is permitted by the above code(1). This resulted in considerable reserve strength in comparison with the six storey frame.

The vigorous shaking imposed by the Pacoima Dam motions on the 6 storey frames was surprising. The response spectra presented in Fig. 2 did not indicate this and for this reason this excitation was not considered in the initial study(14).

It is pointed out that the dynamic 
magnification factor, $\omega$, of the design procedure employed, implied $28 \%$ and $80 \%$ increase of the initial column moments, derived from the elastic analysis for the specified lateral static load, for the 6 storey and the two taller frames respectively. Thus columns of the 6 storey frame possessed considerably less reserve strength. Moreover, the higher mode responses appeared to have a larger influence on the column moment pattern for this smaller frame than anticipated.

The responses to the $E l$ Centro excitation indicate that probably all frames would have been repairable. Unexpectedly, dominant higher mode shapes did not affect the critical column moments. Rather, first mode distortions of the frames were somewhat aggravated by second mode shapes that superimposed themselves. This resulted in critical moments being developed at the bottoms or the tops of columns in a number of adjacent storeys: An example of this can be seen in Fig. 1.

\section{3 - Beam Behaviour}

During instants of the most severe motions, beams in most storeys developed plastic hinges, even in the 18 storey frame. As stiffness degradation of the beams was not considered in the analysis, the number of simultaneously hinging beams was probably overestimated by the analysis.

The predicted plastic hinge rotations remained in all cases below 0.035 radians, a quantity considered to be readily attainable in well detailed reinforced concrete beams. Stiffness degradation in the real structure may, however, result in some increase in the displacement response and as a consequence in some increase of ductility demand.

\section{4 - The Response of Columns}

With the exception of the base, no column yielding was indicated by the analysis for the 12 and 18 storey frames during any of the selected ground motions. The moment envelopes indicate, however, that at least in the lower half of these frames, at some instants during the very severe excitations, the moment demand for the columns was close to the design value.

Ductility demands in column hinges, that developed in the upper storeys of the 6 storey frame during the Pacoima Dam excitation, were small. It is likely that with a small increase in column strength the likelihood of column yielding at upper storeys of this structure could be eliminated even for this extreme disturbance.

The high degree of protection against column hinging was achieved with the use of near minimum reinforcement content in relatively small columns. To comply with stipulated drift limitations (1) these columns could not have been reduced significantly in size.

For the taller frames the design appears to indicate unnecessary conservatism for column moments in the upper storeys.

Hinge formation at column bases points to very careful detailing for confinement, particularly for the exterior columns, where the total axial compression approached the maximum intensity considered to be acceptable $(7,21)$. Significant ductility demand at column hinges of the taller frames was predicted only for the Pacoima Dam excitations.

The design axial loads used are considered to be well within acceptable proximities of those predicted by the dynamic analysis. Inevitable errors in the estimation of earthquake induced axial loads affect only the flexural capacities of the column sections which, in general, have been generously catered for by the proposed design procedure.

As intended the design procedure predicted conservatively shear demand for all columns. The conservatism did not result in unnecessary shear reinforcement.

The lightly reinforced columns, designed in accordance with these principles, are likely to result in an easing of existing construction difficulties.

\section{5 - Further Developments}

It is intended to examine similar frames, designed to possess lower seismic resistance, corresponding with requirements for zones of lower seismic risks, to ensure that a similar degree of protection against column hinging can be maintained.

A re-examination of low rise frames, typically 6 storeys, designed with increased dynamic magnification factors, $\omega$, and that of taller frames with reduced $\omega$ factors for the top storeys, is indicated, to arrive at a more uniform protection of columns for the entire range of multi-storey frames.

Analyses indicated that the lateral load resistance of these frames was not seriously effected by $P$-delta effects. However, further studies are required to examine the influence of stiffness degradation and storey drift on the inelastic dynamic response of frames, before additional specific strength requirements to accommodate P-delta moments, can be recommended for inclusion into building codes.

The continuation of this study may lead to improved dynamic moment magnification and as a consequence, to a drastic relaxation in the requirement for the confinement of upper storey columns. Moreover, the elimination of plastic hinge formation in upper storey columns will result also in a reduction of shear reinforcement in the end regions and in improved performance of beam-column joints. It appears that the savings in transverse column reinforcement and the increased working space at end regions, would more than offset the increase in longitudinal column reinforcement that may occasionally be required.

\section{ACKNOWLEDGEMENT}

A substantial part of the design and some of the investigation of the frames reported here was performed by $R$. D. Jury (1978) who continued the work of D. G. Row (1973), T. E. Kelly (1974) and G. H. Lindup (1975) as part of a research program undertaken at the University of Canterbury under the direction of the author. The invaluable 
assistance of T. E. Kelly of the New Zealand Ministry of Works and Development, Structural Head Office, in performing independent

analyses for each frame, using a modified DRAIN 2D programme, is particularly appreciated. This project would not have been possible without the active participation and advice of Dr. A. J. Carr, Senior Lecturer in Civil Engineering, who extended and improved the original analysis programme developed by R. D. Sharpe in 1972, and who, since the inception of this project, rendered invaluable assistance to all participants.

\section{REFERENCES}

1. New Zealand Standard : Code of Practice for General Structural Design and Design Loadings for Buildings, NZS 4203 : 1976, Standards Association of New Zealand, $80 \mathrm{pp}$

2. SEAOC, "Recommended Lateral Force Requirements and Commentary", Seismology Committee, Structural Engineers Association of California, San Francisco, 1974, $146 \mathrm{pp}$.

3. "National Building Code of Canada 1977", Associate Committee on the National Building Code, National Research Council of Canada, Ottawa, NRCC 15555, pp. 374.

4. Park, R. and Paulay, T., "Reinforced Concrete Structures", John Wiley and Sons, New York, 1975, 769 pp.

5. Paulay, T., "Seismic Design of Ductile Moment Resisting Reinforced Concrete Frames, Columns - Evaluation of Actions", Bulletin of the New Zealand National Society for Earthquake Engineering, Vol. 10, No. 2, June 1977, pp. 85-94.

6. Paulay, T., "An Application of Capacity Design Philosophy to Gravity Load Dominated Ductile Reinforced Concrete Frames", Bulletin of the New zealand National Society for Earthquake

Engineering, Vol. 11, No. 1, March 1978, pp. 50-61.

7. Draft New Zealand Standard DZ 3101 Code of Practice for the Design of Concrete Structures, Parts 1 and 2, Standards Association of New Zealand, 1978.

8. Muto, K., "Seismic Analysis of Reinforced Concrete Buildings", Skokoku - Sha, Japan, 1965 (Revised Edition).

9. ACI Committee 318, "Building Code Requirements for Reinforced Concrete (ACI 318-77) ", American Concrete Institute, Detroit, 1977, 102 pp.

10. Paulay, T., "Moment Redistribution of Continuous Beams of Earthquake Resistant Multistorey Reinforced Concrete Frames", Bulletin of the New Zealand National Society for Earthquake Engineering, Vol. 9, No. 4, Dec. 1976, pp. 205-212.

11. ATC, "Tentative Provisions for the Development of Seismic Regulations for Buildings", Applied Technology Council, ATC 3-06, NBS SP510, NSF 78-8,

Washington, June 1978, $505 \mathrm{pp}$.

12. Row, D. G.," "The Effects of Skew Seismic Response on Reinforced Concrete Frames", Master of Engineering Report, University of Canterbury, 1973, pp. 35-83.

13. Kelly, T. E." "Some Seismic Design Aspects of Multistorey Concrete Frames", Master of Engineering Report, University of Canterbury, 1974, $163 \mathrm{pp}$.

14. Jury, R. D., "Seismic Load Demands on Columns of Reinforced Concrete Multistorey Frames", Master of Engineering
Report, University of Canterbury, 1978, $129 \mathrm{pp}$.

15. Sharpe, R. D., "The Seismic Response of Inelastic Structures", Ph.D. Thesis, University of Canterbury, 1974, $126 \mathrm{pp}$.

16. Powell, G. H., "DRAIN - 2D Users Guide" Report No. EERC 73-22. Earthquake Engineering Research Center, University of California, Berkeley, 1973.

17. Berrill, J. B., "A Comparison of Several Strong Motion Accelerograms" in manuscript, University of Canterbury, Christchurch, New Zealand, 1979.

18. Jennings, P. C., Housner, G. W. and Tsai, N. C., "Simulated Earthquake Motions", California Institute of Technology Research Report, April $1968,22 \mathrm{pp}$.

19. Powell, G. H. and Row, D. G., "Influence of Analysis and Design Assumptions on Computed Inelastic Response of Moderately Tall Frames", Earthquake Engineering Research Center, University of California, Berkeley, Report No. EERC 76-11, April 1976, 111 pp.

20. Paulay, T., "A Consideration of P-Delta Effects in Ductile Reinforced Concrete Frames", Bulletin of the New Zealand National Society for Earthquake Engineering, Vol. 11, No. 3, Sept. 1978, pp. $151-160$.

21. Park, R., "Seismic Design of Ductile Moment Resisting Reinforced Concrete Frames - Columns Subjected to Flexure and Axial Load", Bulletin of the New Zealand National Society for Earthquake Engineering, Vol. 10, No. 2, June 1977, pp. 95-101.

Paper received 31 January, 1979. 
Table I. PRINCIPAL DATA FOR THE PROTOTYPE FRAMES STUDIED

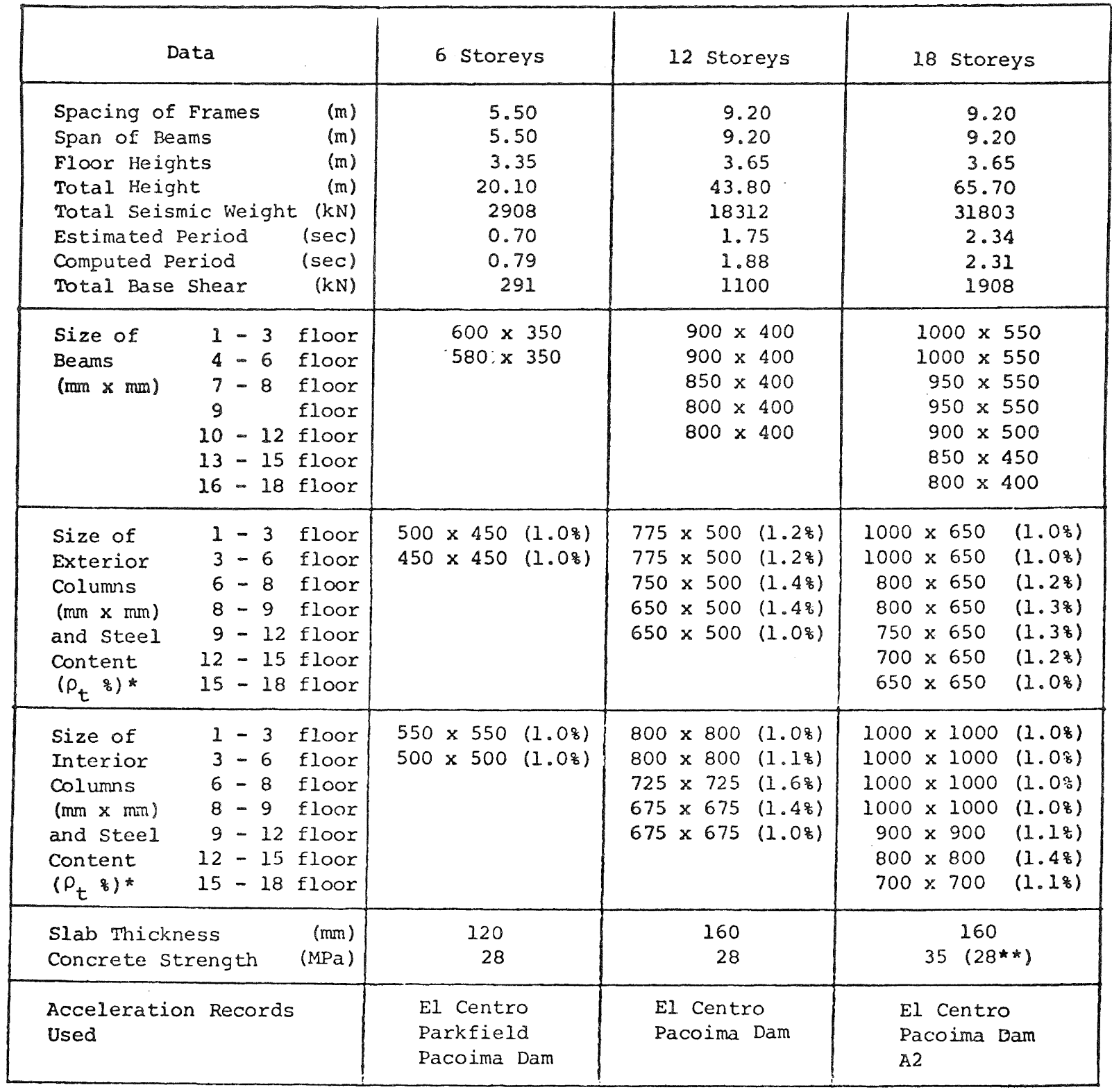

* Total longitudinal reinforcement as an approximate percentage of the gross column sectional area.

** Above 7th floor 


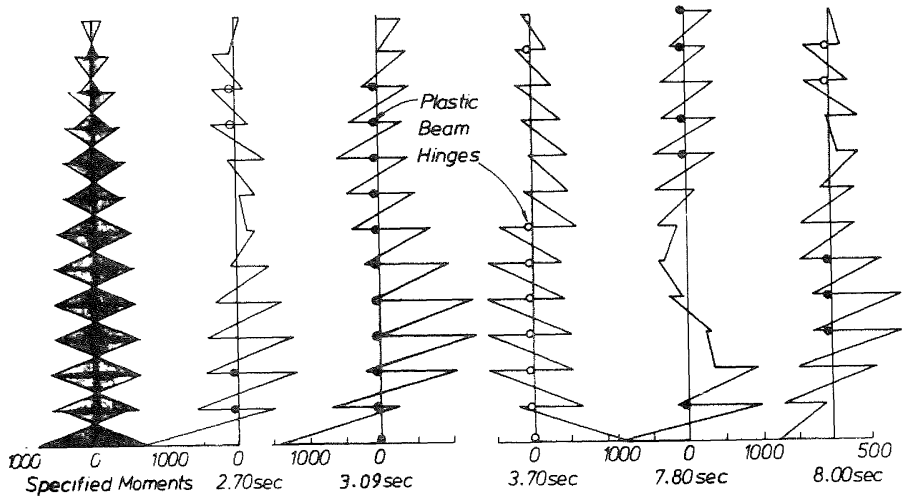

FIGURE 1: A COMPARISON OF BENDING MOMENT PATTERNS FOR AN EXTERIOR COLUMN OF A 12 STOREY FRAME ENCOUNTERED AT INSTANTS OF THE PACOIMA EARTHQUAKE MOTIONS WITH MOMENTS DERIVED FROM CODE SPECIFIED LATERAL STATIC LOADING

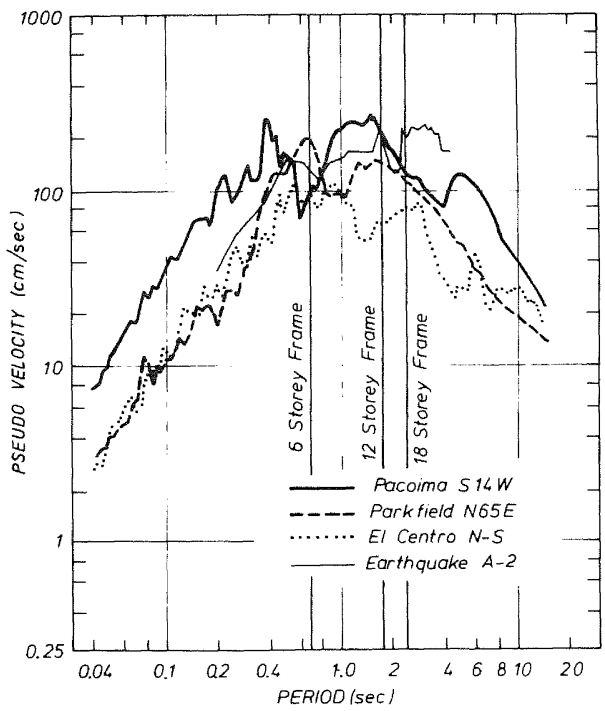

FIGURE 2: PSEUDO-VELOCITY RESPONSE SPECTRA FOR EARTHQUAKES USED IN THIS STUDY.
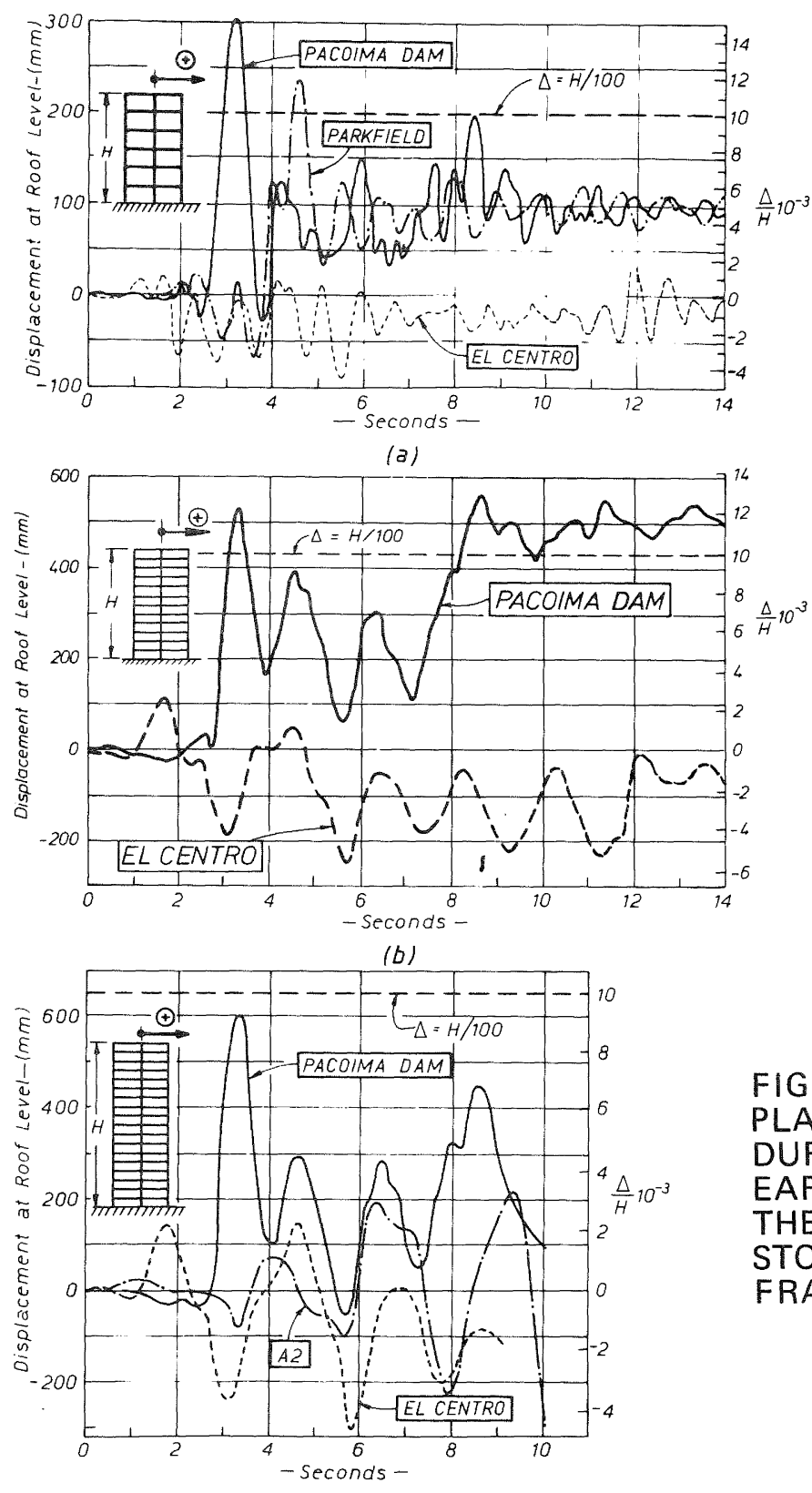

FIGURE 3: HORIZONTAL DISPLACEMENTS AT ROOF LEVEL DURING THE SELECTED EARTHOUAKE MOTIONS FOR THE (a) 6 STOREY, (b) 12 STOREY AND (c) 18 STOREY FRAMES 


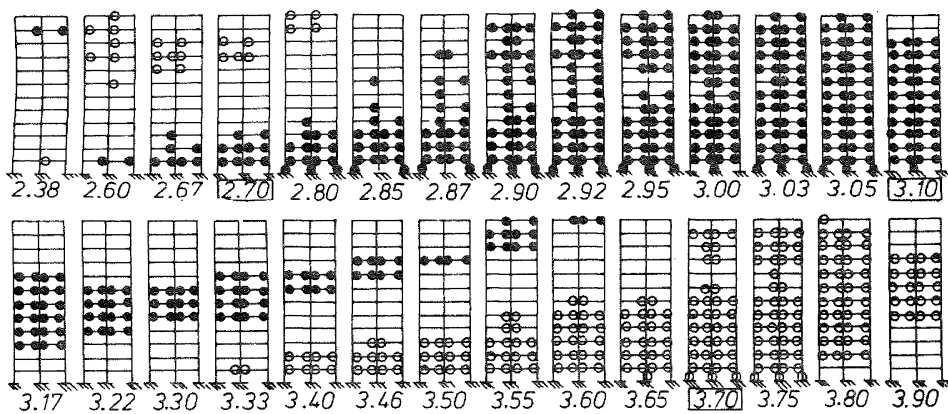

FIGURE 4: PLASTIC HINGE DEVELOPMENTS IN AND STOREY DEFLECTIONS OF THE 12 STOREY FRAME DURING THE PACOIMA DAM EARTHQUAKE MOTIONS
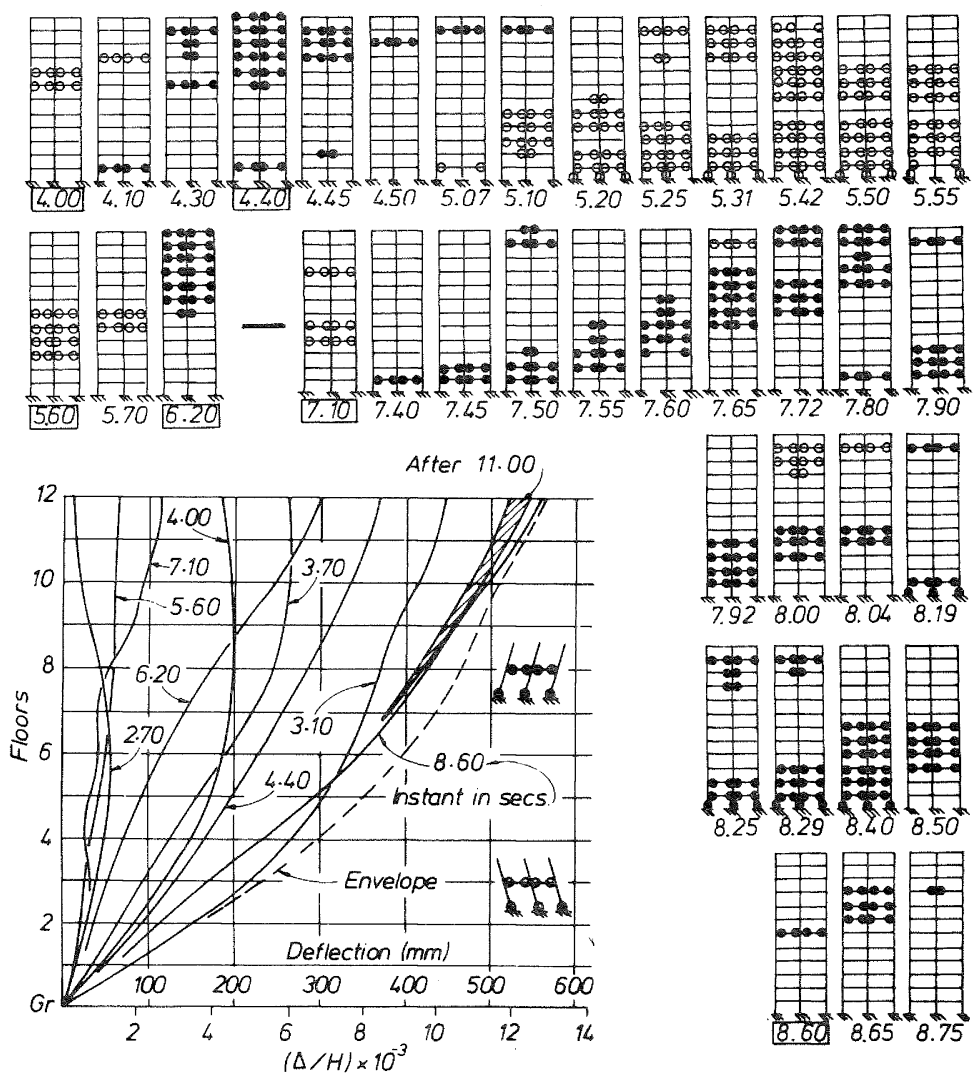

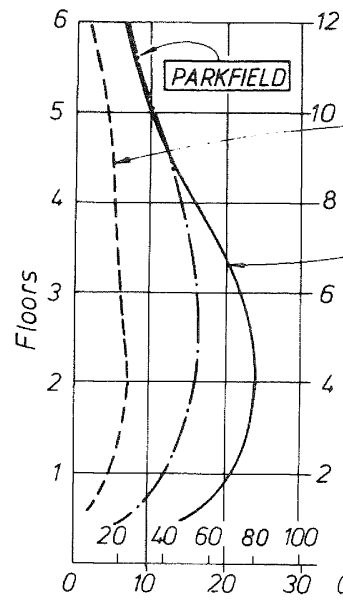

(a)

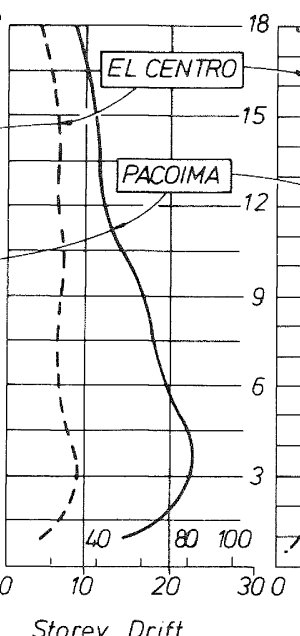

(b)

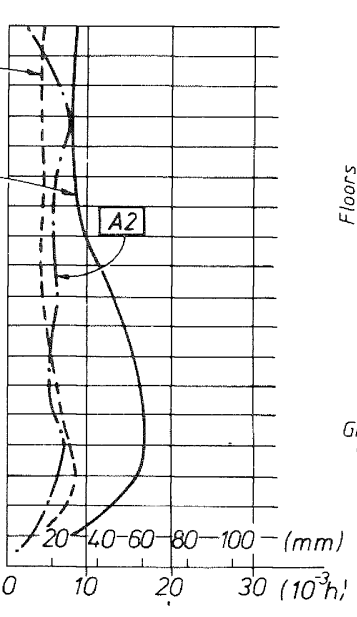

(c)

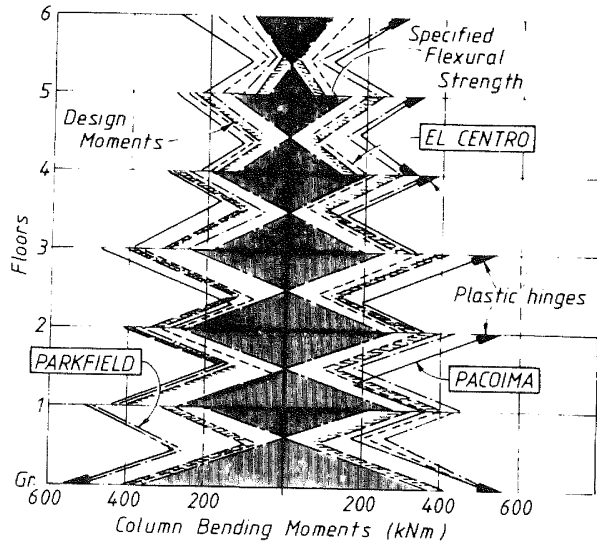

FIGURE 6: BENDING MOMENT ENVELOPES FOR THE INTERIOR COLUMN OF THE 6 STOREY FRAME

FIGURE 5: INTERSTOREY DRIFT ENVELOPES FOR THE (a) 6 STOREY (b) 12 STOREY (c) 18 STOREY FRAMES 


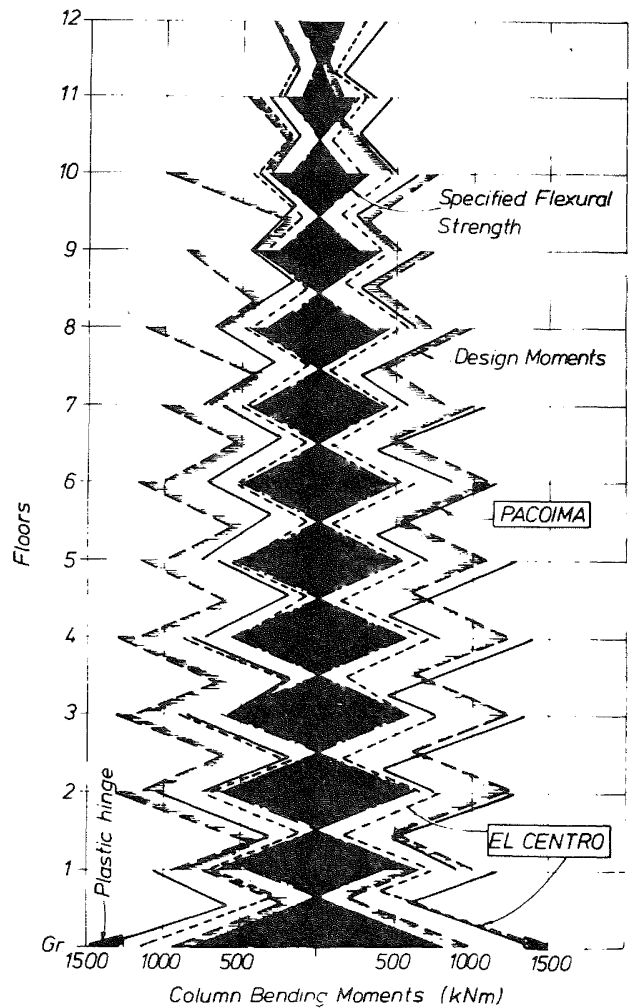

FIGURE 7: BENDING MOMENT ENVELOPES FOR THE EXTERIOR COLUMN OF THE 12 STOREY FRAME

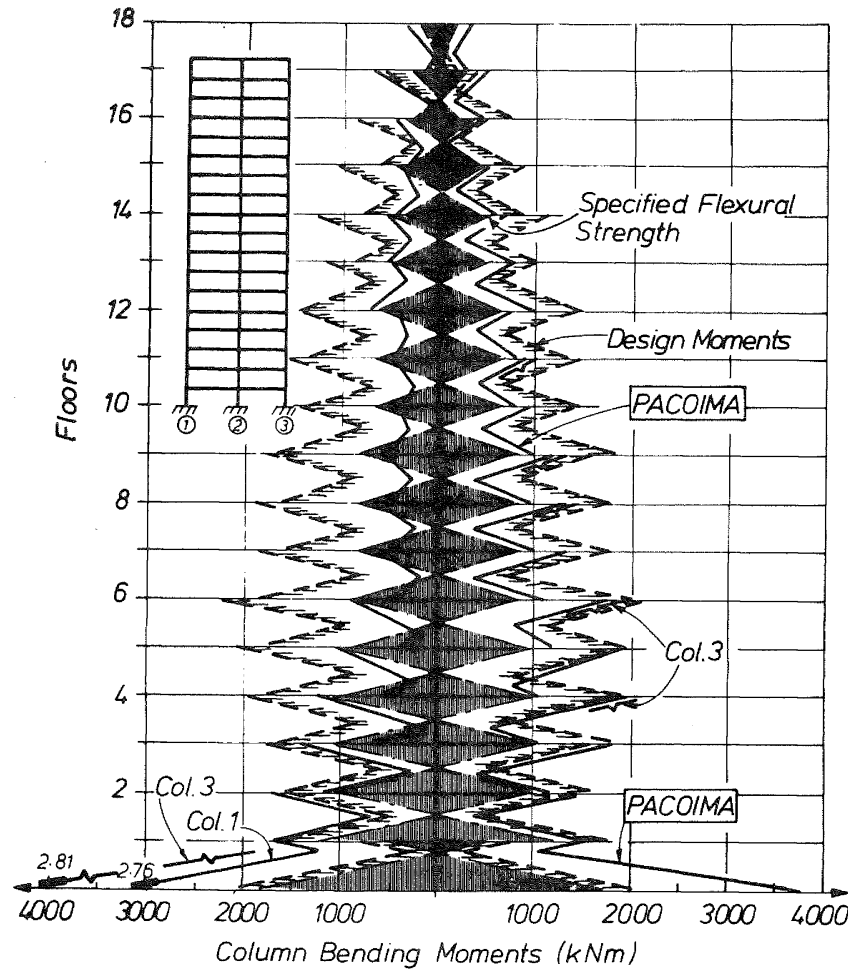

FIGURE 8: BENDING MOMENT ENVELOPES FOR THE EXTERIOR COLUMNS OF THE 18 STOREY FRAME

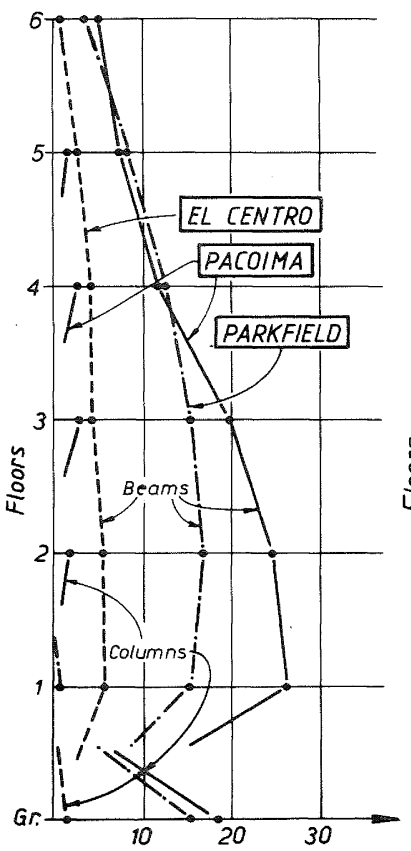

(a)

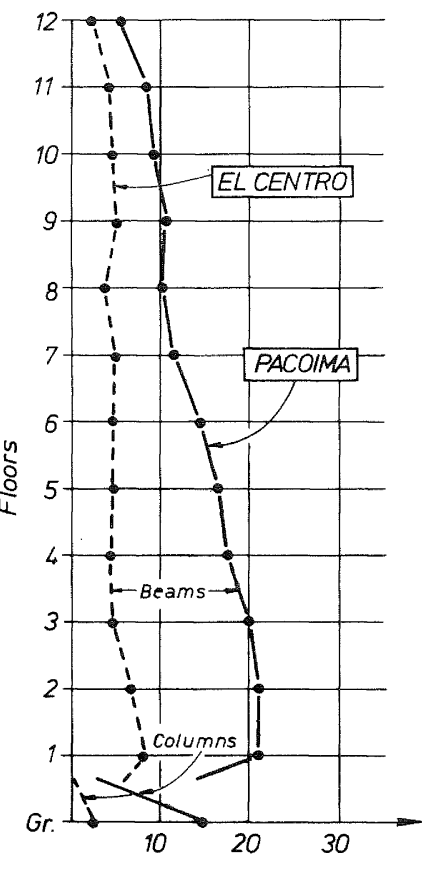

(b)

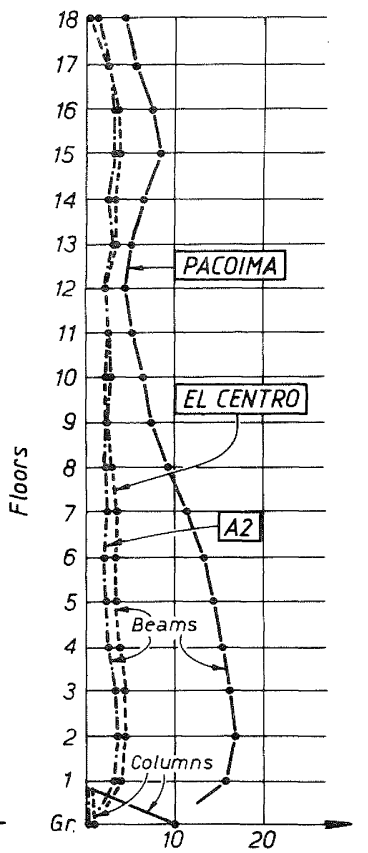

(c) 

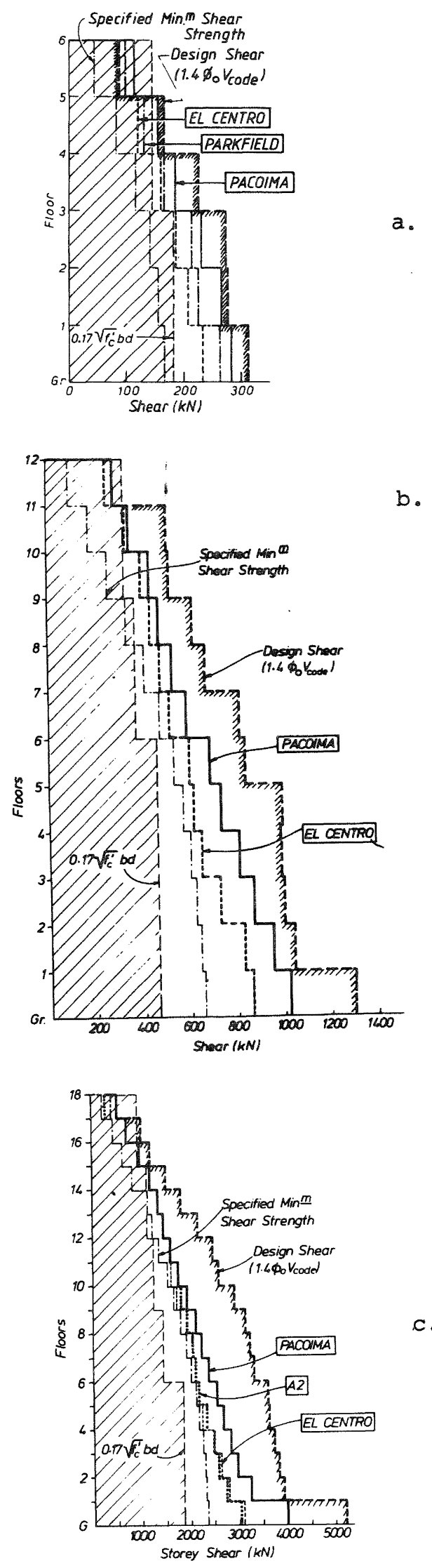

FIGURE 10: A COMPARISON OF ENVELOPES FOR THE SHEAR FORCE ACROSS THE INTERIOR COLUMN OF THE (a) 6 STOREY AND (b) THE 12 STOREY FRAME AND (c) ACROSS THE THREE COLUMNS OF THE 18 STOREY FRAME.
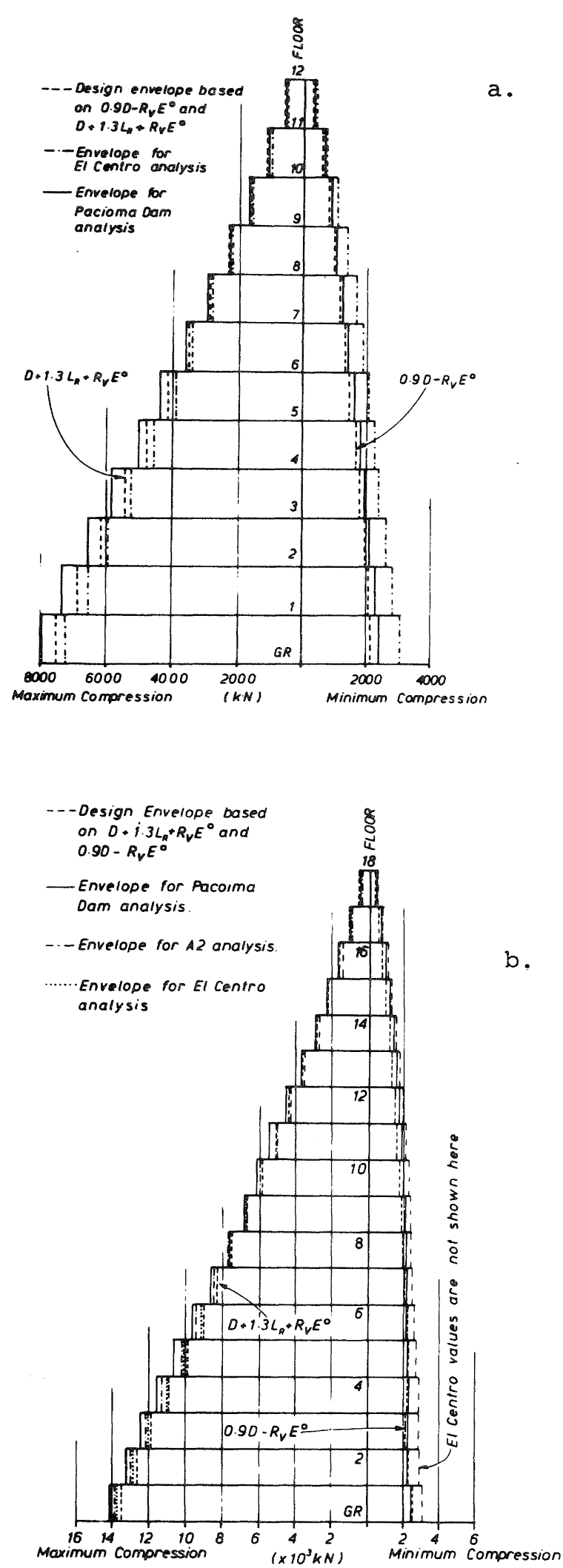

FIGURE 11: ENVELOPES FOR THE MAXIMUM AND MINIMUM TOTAL AXIAL COMPRESSION FORCES IN THE EXTERIOR COLUMNS OF THE (a) 12 STOREY AND THE (b) 18 STOREY FRAME. 